\title{
Erratum to: Partially non-ergodic region specific GMPE for Europe and Middle-East
}

\author{
Sreeram Reddy $\operatorname{Kotha}^{1} \cdot$ Dino Bindi $^{1} \cdot$ Fabrice Cotton $^{1}$
}

(C) Springer Science+Business Media Dordrecht 2016

\section{Erratum to: Bull Earthquake Eng (2016) 14:1245-1263 DOI 10.1007/s10518-016-9875-x}

We regret that the units of measure in Table 1 given by Kotha et al. (2016) are wrong. The correct units are $\left(\mathrm{m} / \mathrm{s}^{2}\right)$ instead of $(\mathrm{g})$. Therefore, the correct version of the note at the bottom of Table 1 is "Units of estimated PGV is $(\mathrm{m} / \mathrm{s})$, PGA and SA $(\mathrm{T})$ are estimated in $\left(\mathrm{m} / \mathrm{s}^{2}\right)$ ". As a consequence, the values on the vertical axis of Figures 5, 6, and 7 are also in $\left(\mathrm{m} / \mathrm{s}^{2}\right)$ and not in $(\mathrm{g})$.

The online version of the original article can be found under doi:10.1007/s10518-016-9875-x.

\section{Sreeram Reddy Kotha} sreeram@gfz-potsdam.de

1 GFZ German Research Centre for Geosciences, Telegrafenberg, 14473 Potsdam, Germany 